\title{
Analysing the Relationship between Learning Styles and Navigation Behaviour in Web-Based Educational System
}

\author{
Nabila Bousbia* \\ LMCI, Ecole nationale Supérieure d'Informatique (ESI) \\ BP 68M, 16270, Oued-Smar, Algiers, Algeria \\ E-mail: n_bousbia@esi.dz

\section{Issam Rebaï} \\ Telecom Bretagne, Computer Science Department \\ Technopôle Brest-Iroise, CS 83818 29238, Brest cedex 3, France \\ E-mail: issam.rebai@telecom-bretagne.eu
}

\section{Jean-Marc Labat}

LIP6, Laboratoire de Paris 6

104, Avenue du Président Kennedy, 75016, Paris, France

E-mail: jean-marc.labat@lip6.fr

\author{
Amar Balla \\ LMCI, Ecole nationale Supérieure d'Informatique (ESI) \\ BP 68M, 16270, Oued-Smar, Algiers, Algeria \\ E-mail: a_balla@esi.dz \\ *Corresponding author
}

\begin{abstract}
The aim of our research is to automatically deduce the learning style from the analysis of browsing behaviour. To find how to deduce the learning style, we are investigating, in this paper, the relationships between the learner's navigation behaviour and his/her learning style in web-based learning. To explore this relation, we carried out an experiment with 27 students of computer science at the engineering school (ESI-Algeria). The students used a hypermedia course on an e-learning platform. The learners' navigation behaviour is evaluated using a navigation type indicator that we propose and calculate based on trace analysis. The findings are presented with regard to the learning styles measured using the Index of Learning Styles by (Felder and Solomon 1996). We conclude with a discussion of these results.
\end{abstract}

Keywords: Learning style, navigation behaviour, trace analysis.

Biographical notes: Nabila Bousbia received the M.S. degree in Computer Science from the School of Computer Science (ESI), Algeria, in 2005. She is now a lecturer there. She is pursuing a Ph.D degree in Computer Science under a joint supervision of ESI, Algeria, and Paris 6 University, France. Her research interests include trace analysis, user modelling and learning styles. 
Issam Rebaï is an associate professor in the Department of Computer Science at Telecom Bretagne Engineering School in France. He received his Ph.D. from the University of Paris, Descartes, in 2006. His dissertation focused on the design and the development of a platform allowing the capitalization of software components for interactive learning environments. He then joined the CNRS in 2008 as a postdoctoral fellow at the LIMSI Computer Science Laboratory. He conducted research on ambient environments, emotions, and robotics. His research interests include learning metadata, affective and ubiquitous computing.

Jean-Marc Labat is full Professor in computer science at Paris6 University. He is head of a research team within the Lip6 laboratory and leads the UTES, a university joint service. He is the current president of the ATIEF association. His research focuses generally on cognitive modelling of user experiencing problem solving. His current research goals are to investigate serious games.

Amar Balla received the Ph.D. degree on Computer Science from the School of Computer Science (ESI), Algeria, in 2005; and then a clearance to conduct research. He is head of a research team within the LMCS laboratory and leads a department at the ESI School. His research interests mainly focus on adaptative hypermedia and student modelling.

\section{Introduction}

The use of computers in education brings new opportunities, every day. Research in this field, or more generally in the field of learner modelling, was focused mainly on detecting features related to the learner's knowledge, interests, goals, background, and individual traits (Brusilovsky and Millán 2007). We are interested in this last aspect, in particular in the learning style.

Learning styles refer to how individuals prefer to organize and represent information (Reed and Oughton 1997). The learning style is thus connected to both a set of behaviours - strategies in the way of managing and organizing the information, as well as the way of implementing these behaviours and strategies.

Thus, several studies on Educational Hypermedia Systems (EHS) have used learning styles (LS), these last years, as a criterion for adaptation and tracking to improve the learning results. In fact, the integration of this theory in a computer environment allows us to consider the learning style of each learner individually, by adapting the content, in terms of form, structure, presentation order of learning activities and choices of these activities, which is a difficult or impossible task for the teacher in a traditional training situation with a group or a class of learners.

However, given the variety of definitions of the learning style concept, several learning style models were proposed in the literature (over 70 according to Coffield and al. (2004)). Some of them were implemented in educational hypermedia systems (WHURLE, CS383, ILASH, etc. (Brown et al. 2005)). The detection of these styles rests on questionnaires proposed for each model (ILS (Felder and Solomon 1996), LSQ (Honey and Mumford 1992), etc.).

Our interest concerns the automatic detection of learning styles, in a web-based learning, by the analysis of the learner's behaviour through the collection and the interpretation of traces on the learner's activities. 
To address this issue, the aim of this paper is to examine the relationships between the learning styles and the learner's navigation behaviour in a web-based learning environment, in order to provide information that can be used in the detection process. We propose to use observable indicators describing the navigation behaviour through a navigation typology.

In this paper, we first describe the learning style theory and its implementation in educational hypermedia systems (EHS). In Section 3, we explain our approach to deduce the learning style from behavioural indicators. Section 4 presents the methodology of the experiment. Section 5 details and discusses the results to point out some guidelines to deduce the learning styles from trace analysis. Section 7 finally concludes the paper.

\section{Background}

\subsection{Learning Style}

Cognitive psychology has long focused on individual differences and their impact on learning (Ayersman and von Minden, 1995; Liu and Reed, 1994). In search of practical means to respect these differences, research was directed towards the concept of "learning style" relating to the individual's learning preferences (Brusilovsky and Millán 2007). However, a simple reference to the literature highlights the plurality and the diversity of definitions. To clarify this concept, Chevrier et al. (2000) organize them within three categories, according to whether they refer to: (i) a specific way of behaving, predisposition, or preferences related to learning and teaching contexts; (ii) information processing; or (iii) personality characteristics.

A definition gathering these three aspects is given by Riding and Rayner (2001): "The expression learning style refers to a set of individual differences, which include not only an expressed personal preference concerning teaching or an association with a particular form of learning activity, but also to individual differences that can be found in the psychology of intelligence or personality."

The learning style is thus connected to both a set of behaviours - strategies in the way of managing and organizing the information, as well as the way of implementing these behaviours and strategies.

In this way, various theories of learning styles have been developed with an increasing frequency during the last decades. Coffield et al. (2004) identified 71 models. To have an overview of these different theories, researchers like DeBello (1990), Chevrier et al. (2000), Riding and Rayner (2001), Cassidy (2003) and Coffield et al. (2004), set typologies or categorizations of these models by identifying the different dimensions of the learning style. The analysis of some classifications leads us to say that they all try to distinguish the three elements of definitions, namely preferences (sensory or environment), the cognitive ability / personality, and the learning process (experiential, data processing, learning strategy, etc.). They are largely based on the Curry's 'onion' model (Curry 1983).

In addition to this vast collection of learning style theories, there is also a wealth of confusing terminology (Brown et al. 2005). For example, the terms 'learning style', 'cognitive style' and 'information processing style' are all terms that have been used interchangeably by various researchers, mainly due to their particular position concerning whether learning styles are stable or not over time. The term 'learning style' has been used in this paper as an overarching term that is meant to include any psychological or 
educational model used in research into cognitive processes applied to a learning situation. We also consider that it is flexibly stable according to the situations and the context. Consequently, the detection of the learning style, allows learning individualization and its improvement through the discovery of learner's preferred learning strategies as well as the adapted situations and teaching (Chevrier et al. 2000).

\subsection{Learning Style and EHS}

In the specific context of online learning, research on learning styles (LS) is still in a preliminary and exploratory stage (Brusilovsky and Millán 2007). The overall objective of the use of learning styles in such a context is the adaptation and customization of learning.

In terms of used LS model, the current EHS use some existing learning style models from those considered as the most popular. The majority of these EHS take only one learning style model into account, or a portion of its dimensions or preferences. Felder and Silverman's model (Felder and Silverman 1988) remains the most widely used. The reasons behind its popularity are summarized by (Brown et al. 2006), in (Popescu 2008), who justify their choice for FSLSM with the fact that it fulfils most of the required criteria: (i) the model should be able to quantify learning styles (and hence model them computationally); (ii) the model should display a good degree of validity and reliability/internal consistency (and thus provide accurate evaluations of learning style); (iii) the model should be suitable for use with an adaptive web-based educational system; iv) the model should be suitable for use with multimedia; (v) the model should be easily administered to university students. Furthermore, as (Sangineto et al. 2007) noted, FSLSM was widely experimented and validated on an engineering student population. Moreover, although other models may have stronger theoretical foundations, FSLSM contains useful pragmatic recommendations to customize teaching according to the students' profiles (Popescu 2008). For all these reasons, we have chosen to use FSLSM in our experiment, presented in the coming sections.

However, it should be noted that most learning style theories, proposed in psychology literature, are conceived for traditional face-to-face educational settings, not for computer-mediated instruction (Popescu 2009). Indeed, no model of learning style has been proposed to inform on how learners work with digital resources. So, how can these theories be then used in hypermedia learning environments?

The studies presented by the authors of EHS indicate a positive influence of use of learning styles in such hypermedia learning environment (Carver et al. 1999) (Papanikolaou et al. 2003), (Sangineto et al. 2007), (Triantafillou et al. 2003), (Wang et al. 2008). Thus, attempts to design learning style models for EHS, based on existing ones, have been proposed. In (Brown et al. 2005), the authors suggest creating a classification of LS that can be used with a learner model by adding layers to the Curry's model. (Popescu et al. 2007) construct a model from the various existing LS models, including learning styles satisfying a set of conditions. Our work joins these studies that propose a learning style model from the existing ones. Therefore, how can we differentiate these learning styles?

For the LS identification, the existing systems generally ask learners to complete a psychological questionnaire, the one proposed by the authors of the LS model (e.g. Index of Learning Style (ILS) (Felder and Solomon 1996) of the FSLSM). Other systems require from learners to explicitly express their learning styles at the beginning of the course. The result is stored in the learner model, which is usually not updated, except in some systems where the update is directly activated by the student or activated 
automatically according to the assessment results. Learners are therefore classified as stereotypes.

However, this approach of identifying learning styles raises several issues. We must ask the learner the right questions, to assign him/her a style and adapt the system. However, as Rich (1999) pointed out, individuals are not reliable sources of information about themselves. Indeed, questionnaires, in general, face the problem that the answers may not correspond to the actual behaviour that questions are designed to check (Draper 1996; Paredes and Rodríguez 2004). Furthermore, the use, in general, of questionnaires, as a tool for identifying learning styles, is based on several assumptions (Graf 2007): Firstly, the assumption is made that students are motivated to fill out the questionnaire properly and to the best of their knowledge about their preferences. Secondly, filling out a questionnaire about the preferred way of learning requires that the students are aware of their preferred way of learning. However, Stash, Cristea, and de Bra (2006), for example, identified that the Masters students participating in their study about adaptation to learning styles had only little meta-knowledge on their learning preferences. Thirdly, the social and psychological aspects, such as the students' beliefs about how people should behave, can influence their answers on the questionnaire. Additionally, using questionnaires for identifying learning styles underlies the assumption that the learning styles are stable for a long period of time. However, as discussed before, the stability of learning styles is still a controversial issue. As soon as learning styles change, the results of the questionnaires are no longer valid, students would have to do it again in order to identify their new learning styles. However, this approach would raise new issues, dealing with how to detect the moment when a learning style has changed, and how to update its values?

To answer this question, several new approaches propose to identify and / or update the learning styles based on behaviour analysis (e.g. iWeaver (Wolf 2007), DeLeS (Graf 2007), Welsa (Popescu et al. 2008), (Chang, et al. 2009)). Our work follows this approach. However, we are particularly interested in web-based learning environments. This is why, in the next section, we explore studies on the relationships between learning styles and the learner's behaviour on the Web.

\subsection{Learning Style on the Web}

In order to examine the relationships between learning styles and learners' behaviour on hypermedia, several studies in psychology, education and computer science have been conducted. They have all shown a strong relationship between learners' learning styles and their search and navigation behaviour in Web applications. Moreover, some studies have concluded that beyond explaining behaviour through learning styles, it is also possible to deduce the styles from the analysis of these behaviours (Chen and Liu 2008), which is the aim of our study. However, before explaining our proposal, we examine in the following some of this research and their findings.

The learning style model proposed by (Witkin et al. 1971) (field dependence or independence) has been the most studied, particularly in terms of format, accessibility, structure and performance.

Regarding the format, several studies suggest that learners with field independent style could particularly benefit from the choice of media (text, animation, voice). Studies by (Chuang 1999), (Chan-Lin 1998), (Lee 1994), and (Marrison and Frick 1994) have focused on this aspect. The work of (Ghinea and Chen 2003) also states that they prefer 
detailed resources, as these field independent learners are more likely to have analytical LS (Jonassen and Grabowski 1993) (Reed et al. 2000).

As for accessibility, (Ford and Chen 2000) conducted a study to examine how learning styles influence users' browsing behaviour on the Web. (Palmquist and Kim 2000) and (Chen, Magoulas and Macredie 2004) studied the influence of cognitive style on web search. The work of (Chen and Liu 2008) focused on the effects of the learning style on learning paths. These studies found that field dependent users promote the use of site maps to get an overview of the context and tend to follow the links provided by the Web page, especially for novices. However, field independent users use the index more to locate a particular point and tend to use search engines, search function, and usually URLs to reach the websites.

In terms of structure, (Dufresne and Turcotte 1997) (Reed and Oughton 1997) (Lee et al. 2005) examined users' performance in linear and non-linear information structures. They found that field dependent learners who used the system with the nonlinear structure, spent more time to complete the test than those who used the system with a linear structure.

Finally, the work of (Korthauer and Koubek 1994), (Lu, Yu and Liu 2003) and (DeTure 2004) found that field independent learners are more successful than those dependent upon learning with hypermedia resources.

However, some studies found no difference between field dependent and independent LS on one or all of these aspects. Among these studies, (Marrison and Frick 1994) indicate that there is no difference between field dependent or independent users regarding the usefulness of audio resources in the training environment; (Hwang et al. 2007) concerning the number of annotations made, and (Shih and Gamon 2002) (Lu, Yu and Liu 2003) regarding learning behaviour, in general.

For the other learning style models, some authors have echoed the findings for the field dependent and independent LS to other dimensions of LS models. For example in the work of (Chen, Magoulas and Macredie 2004) and (Chen and Liu 2008), the authors argue that field dependent users tend to have global (Pask 1976), passive and external LS, while field independent users tend to be analytic, active, and internal. Therefore, the findings for these two dimensions - field dependent and independent - remain valid for these dimensions.

Besides, other studies have analyzed other dimensions of LS models. The learning styles of the model proposed by Gregorc (1979) have been studied in (Miller 2005) who found that the performance of learners is affected by their learning styles. The dimension verbal/imager proposed by Riding has been studied by (Graff 2005) with respect to navigation strategies. In this study, Graff (2005) finds that users with a verbal style prefer a hierarchical structure, while those with a visual style prefer a relational structure of pages. Regarding Kolb LS model (Kolb 1984), the studies of (Reed and al 2000), (Federico 2000), (Kraus, Reed and Fitzgerald 2001), and (Miller 2005) state that there is no significant difference between the four styles identified by Kolb when learning with hypermedia. The global/analytic LS dimension proposed in several LS models (Felder and Silverman 1988, Pask 1976) was studied by (Kraus, Reed and Fitzgerald 2001), (Calcaterra et al. 2005) and (Peterson and Deary, 2006). In (Kraus, Reed, and Fitzgerald 2001) the authors found that users, with a global style, prefer adapted interface, presenting a synoptic view of the information. However, analytic users fit easily into all types of interfaces and demonstrated strong navigational skills. In this study (Kraus, Reed and Fitzgerald, 2001) also analyzed the visual/verbal dimension and noticed that users 
require an adapted visual interface and have strong navigational skills. Verbal users adapt easily to interfaces. This dimension, visual/verbal, was also analyzed by (Frias-Martinez, Chen, and Liu 2009).

Finally, it is worth noting that these studies are all based on the analysis of navigational behaviour of a sample of users or learners with Web applications. Analysis techniques, with statistical and data mining, have been applied to them, before generalizing these findings, according to which users' behaviour in Web applications varies according to their learning styles.

To summarize, we find, through this study, that though learning styles are not the only source of difference in the users' behaviour on the Web, they are nevertheless a significant factor, influencing the reactions of learners in a hypermedia environment (Calcaterra et al. 2005) (Liegle and Janicki 2006) (Dag and Geçer 2009). Thus, the results of these studies can be used as criteria for the automatic identification of learners' learning styles on Web applications to replace LS questionnaires and solve their problems.

\section{Proposal}

In this research, we aim at having indicators, or a Trace Based System (TBS), which automatically deduces the learner's learning styles by analyzing his/her behaviour (Bousbia et al. 2008). We consider a Web-based learning environment, such as an elearning platform, which provides online educational content to learners with educational activities, and not necessarily contains evaluations.

In this context, we are interested in the digital traces, registered in log files on the learner's side. This approach allows tracing all the learner's activities, even those made outside the learning system: the learner's interactions during his/her browsing path, which are not necessarily prescribed by the content author: navigation within and between educational objects, and also web browsing, personal productions, and any activity done in parallel. Of course, the learner decides the beginning and the end of the recording of its activities on his/her machine. This recording defines a session.

To determine the indicators, we relied on the one hand, on the analysis of feedback that teachers want to have about their students through a survey we made with teachers (Bousbia and Labat 2007). On the other hand, we studied the state of the art on digital traces resulting from learning situations, as well as on the studies about the influence of learning styles on the learner's behaviour in a digital environment, mentioned above.

However, the indicators proposed in the literature to identify the learning styles based on trace analysis are generally quantitative and low-level indicators directly calculated from traces, and usually related to duration or action frequency (eg. number of accesses of recommended learning objects versus not recommended ones (Popescu 2008)). Thus, these indicators are difficult to be interpreted by the teacher. Furthermore, generally these indicators are strongly linked to the EHS used.

We follow a different approach. In order to propose indicators applicable for Web-based educational systems, in general, with qualitative value describing the learning behaviour, we propose a 'navigation type' indicator, inspired from Web Usage Mining studies, mainly the navigation typology proposed by Canter et al. (1985). This indicator classifies the learner's navigation behaviour in four types (Bousbia et al. 2009): 
- Overviewing: this value is close to the Canter "scanning" value. It implies that the learner is covering a large proportion of pages constituting the course. Through this fast reading, the user seeks to acquire an overall "panoramic" view of the course.

- Studying: corresponds to a partial or complete reading of the course pages, with a span of time on each.

- Deepening: is rather close to the preceding value. It describes a learner who remains a relatively long time on a course, careful with details, and seeking Web documents related to the course topics.

- Flitting: close to the Canter "wandering" value. It is a journey without a strategy or a particular goal. The main difference with the overviewing type is the lack of focusing on the course.

This indicator is a qualitative, high-level indicator, derived from low and intermediate level indicators (Bousbia et al. 2009). In fact, we propose to define the indicator calculation methods by first classifying needed indicators at three levels: (i) low-level indicators, having no meaning alone and generally deducted directly from the raw data; (ii) intermediate or composite indicators; and (iii) high-level indicators, with an interpretative value, often derived by a complex treatment of the traces (Dimatricopolou et al. 2004). Then, we define links between these indicators in order to calculate automatically their values from traces to high-level indicators, and then deduce learning styles values. For this end, we also classify the existing learning styles, we think deductable from observable indicators, according to the three definition elements. This helps us to get a classification, or a model in which we need to define the dependence between indicators and learning styles, as shown in figure 1 .

Indeed, we classify learning styles into three layers, each includes one, or more attributes (Bousbia et al. 2008):

- Educational preferences layer: this layer includes attributes related to the preferred learning time, environment preference (individual / group, learning by project, simulation, etc.), information representations, and encoding methods (verbal / visual).

- Learning process layer: includes learning strategy, comprehension, and progression approach.

- Cognitive ability layer: includes motivation and concentration capacity.

The values, of each layer's attribute, are chosen from the existing learning style models, by making their definitions closer. The high-level indicators are therefore involved in determining the attributes of our model. We assume here that the navigation type indicator is involved in the determination of many values of learning styles (see figure 1). To affirm this assumption, we developed an experiment that we present in what follows. 


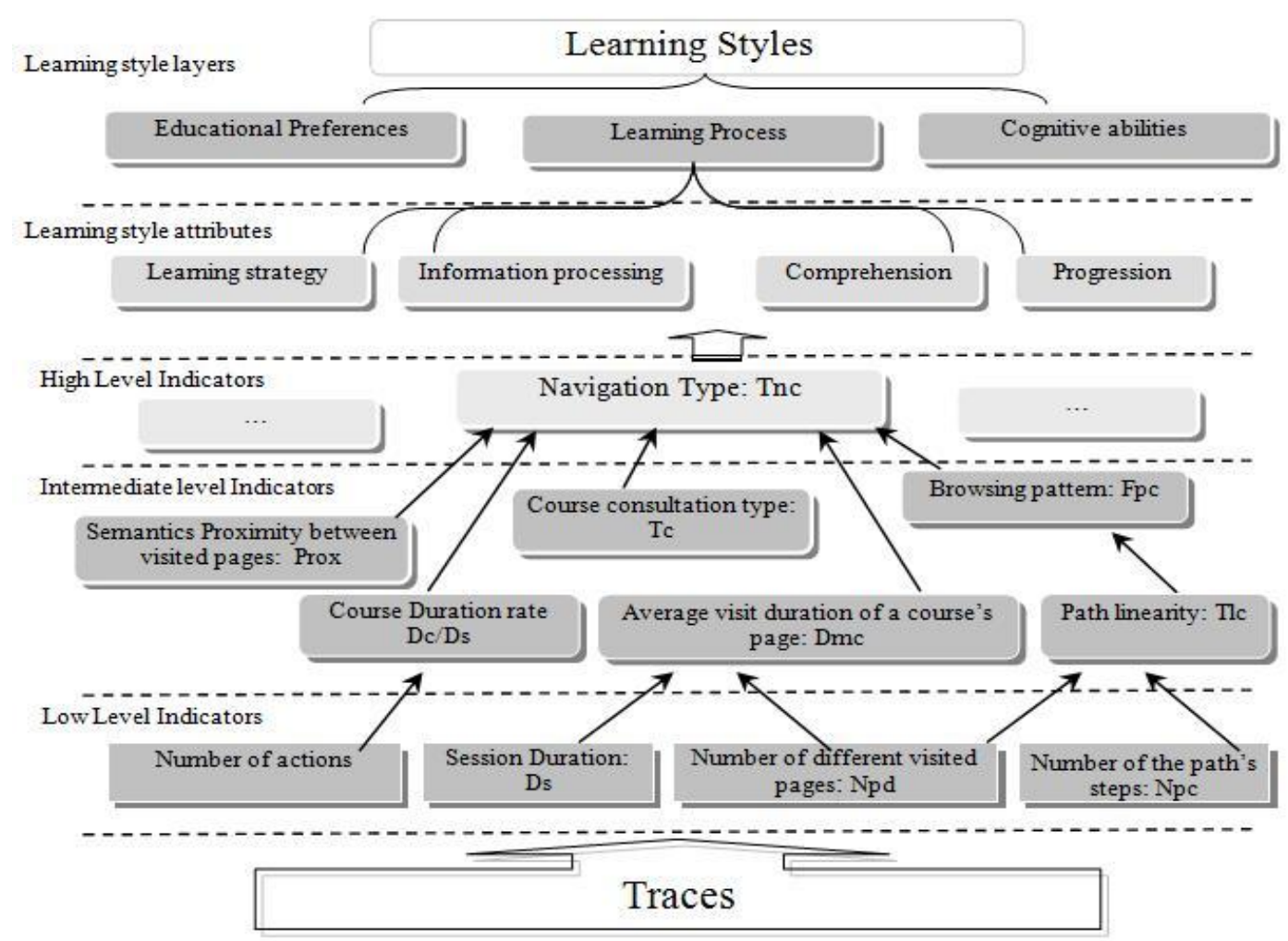

Figure 1. From traces to learning styles

\section{Methodology}

To identify differences in navigation behaviour among different learning style groups, we conducted an experiment at the ESI School. This section describes the research instruments, the participants, the experimental design, and the methods of data analyses.

\subsection{Research Instruments}

Research instruments work as a guide in order to make sure that the same information is obtained from different participants. The research instruments used in this study included a Web based course and a learning style questionnaire to measure students' learning styles.

\subsubsection{Web based Course}

The context of this study was a hypermedia general course about "Computer Security". Its content is in HTML format and mostly contains text. We limited this experiment to such resources to focus on the learner's navigation behaviour from page to page in a Web learning environment. Thus, the activities, considered in this case, are consulting or reading activities that we generally found in all courses available on e-learning platforms. However, the experiment can be repeated with other types of resources, and other activities, using an approach of matching pedagogical resources to the learning styles or a 
mismatching approach to check the learners' behaviour, using the proposed indicators or others.

The course complies with the SCORM ${ }^{1}$ standard. The choice of SCORM was made for two reasons: first, it uses a tree structure, we think the most commonly used in the majority of courses, and which our indicators are appropriate to. Second, SCORM requires a metadata file to include the course keywords, needed to calculate some intermediate indicators.

The content is composed of 53 Web pages, integrated into two chapters: "threats" and "vulnerability". It also includes an introduction and a conclusion. The course consultation is done on the eFAD platform (Bousbia 2005), (Figure 2). The runtime environment includes: (i) the course index, located in the left frame of the browser, offering free access to the resources (the learner can hide this index using the button located above the text); (ii) the platform navigation buttons in the top to visit the pages sequentially; and (iii) the course content in the central frame. The navigation environment also includes the browser interaction objects (the navigation buttons, print, search, next, back, copy /past, etc.) using the keyboard and/or the mouse.

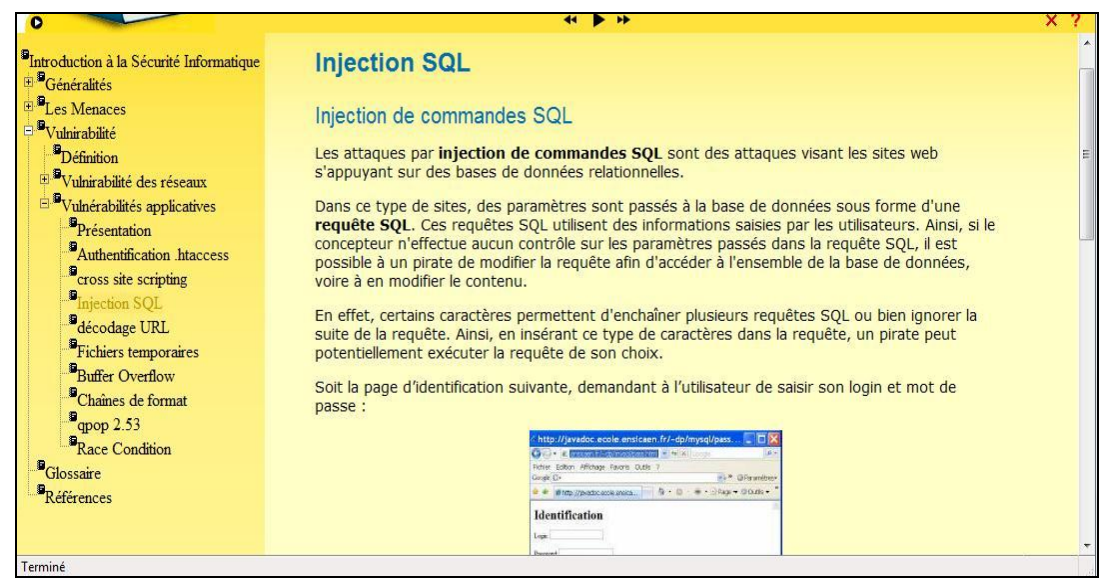

Figure 2. A snapshot of the computer security course on the eFAD platform

\subsubsection{Learning Style Questionnaire}

In this experiment we wanted to investigate several learning style attributes from those defined in our classification. We used two learning style questionnaires widely used in literature: the Group Embedded Figures Test (GEFT) by Witkin et al. (1971) and the Index of learning style (ILS) by Felder and Solomon (1996).

The first evaluates the user's level of field dependence. It presents items containing complex geometrical forms in which the individual is required to find simple shapes on them. The subject's score is the number of simple shapes correctly identified in the complex forms. The maximum total score is 18 . If the score is high, the subject is considered as field independent.

\footnotetext{
${ }^{1}$ Sharable Content Object Reference Model. http://www.adlnet.org
} 
The second presents a 44-item questionnaire for identifying the learning styles according to FSLSM (Felder and Silverman Learning Style Model) (Felder and Silverman 1996). Every learner has a personal preference for each dimension. These preferences are expressed with values between +11 to -11 (with a step of $+/-2$ ) per dimension.

\subsection{Participants}

The experiment involved 116 graduate students at the National School of Computer Science (ESI-Algiers). However, we investigate here only the result of 27 participants, since the data are still being processed. These students are aged between 18 and 24 years, 15 male and 12 female. Their participation was voluntary and they have not attended the course before.

\subsection{Procedure}

The students worked on machines equipped with the trace collection tool, with a personal account on the platform. The observation starts with their connection to the e-learning platform, after activation of the collection tool. During the tests, a human observer (the experimenter) is present in the training room to ensure the normal progress of the experiment. In our case, the human observer is the teacher.

The experiment was conducted in 5 sessions of 10 to 30 minutes. The start and the end time of each session were noted down. The motivation for this choice of short time browsing is the possible change of navigation strategy during the session. For instance, a learner, browsing a course, may suddenly decide to look for precise information.

The first four sessions involved only the first part of the course "threats". We asked the students to accomplish a chosen activity in every session to induce a given navigation behaviour according to the typology proposed in $\$ 2$. For example, a question asks the student to extract the words in bold from a particular course part. This prompts the student to view several pages of this part without having to read them thoroughly. This corresponds to the "Overviewing" behaviour.

In the last session, we asked the students to browse according to their interests and needs through the pages of the second part of the course "Vulnerability", they have not visited yet. Thus, they freely adopted one of the four behaviours that better fit their preferences.

Finally, to characterize the students' learning styles, they were asked to take the GEFT and the ILS tests. However, as all the participants are students in computer science, which is a scientific field, all their scores were high with the GEFT test. We later found this conclusion in (Tinajero and Paramo, 1997, Clark et al. 2000; Pithers, 2002) in (Tyndiuk 2005), who underlined that this test is strongly correlated with academic performance: the science course students often score better than students in literature courses. Therefore, in this study, we only use the results of the ILS test.

\subsection{Data Analysis}

At the end of the experiments, the log files were stored in XML format for processing. Navigation data are sequences of dated events (page access, click, etc.), which are collected throughout the user's session. These traces are then processed to compute behavioural indicators. $27 \log$ files were thus gathered. We divided each log file into 5 
sessions considering the start and the end time of each activity. The four sessions were used to evaluate the navigation type indicator. Their results will not be discussed in this paper. However, we only focus on the last session in order to identify correlation between the navigation type indicator and the learning style attributes.

In order to conduct a comprehensive evaluation, the analysis is performed in two steps. First, we examine the observation distribution in terms of navigation behaviour found with the navigation type indicator over the preference levels of each learning style dimension of the FSLSM. Next, we evaluate the dependence between the two variables: learning style dimension and navigation type indicator. To this end, we use the chi-square test $(\chi 2)$ with a signification level $(\alpha=0.05)$, given that these two variables have qualitative values. This test checks two hypothesises:

H0: The learning styles and the navigation types are independent.

Ha: The learning styles and the navigation types are dependent.

If the calculated $p$-value is higher than the signification level $(\alpha=0.05)$, the assumption $\mathrm{HO}$ is validated. Otherwise, $\mathrm{HO}$ is rejected and $\mathrm{Ha}$ is validated.

\section{Results}

\subsection{Learning Style Distribution}

First, we analyzed the distribution of preferences for each FSLSM dimension. Table 1 summarizes the ILS questionnaire results for the 27 students. The values 1-3 are interpreted as balanced between the two dimensions of the scale. They are associated to a mild preference level. The values 5-7 and 9-11 respectively present a moderate and strong preferences.

Table 1. ILS Questionnaire Results

\begin{tabular}{|l|r|r|r|r|}
\hline \multicolumn{1}{|c|}{ ILS Results } & \multicolumn{1}{|c|}{$\begin{array}{c}\text { 9-11 } \\
\text { (Strong } \\
\text { preference: } \\
\text { STG) }\end{array}$} & $\begin{array}{c}\text { 5-7 } \\
\text { (Moderate } \\
\text { preference: } \\
\text { MOD) }\end{array}$ & $\begin{array}{c}\text { 1 - 3 } \\
\text { (mild } \\
\text { preference: } \\
\text { MLD) }\end{array}$ & Total \\
\hline ACT: Active & 1 & 7 & 9 & 17 \\
\hline REF: Reflective & 0 & 3 & 7 & 10 \\
\hline SEN: Sensing & 5 & 5 & 9 & 19 \\
\hline INT: Intuitive & 3 & 2 & 3 & 8 \\
\hline VIS: Visual & 6 & 9 & 3 & 5 \\
\hline VRB: Verbal & 0 & 2 & 8 & 14 \\
\hline SEQ: Sequential & 1 & 5 & 9 & 13 \\
\hline GLO: Global & 0 & 4 & 7 & 5 \\
\hline
\end{tabular}


The distribution of the participants over the sequential/global dimensions is quite equitable. However, it is less equitable for the other dimensions, mainly for the visual/verbal dimension where only 5 students, with a global learning style, are found. Thus, it is necessary to take into account this distribution during the analysis.

The next step is to analyse the students' log files to identify the navigation type related to each observation.

\subsection{Navigation Type Indicator}

The navigation type indicator is a high level indicator. The calculation of its value is based on five intermediate indicators, as shown is figure 1: (i) the average visit duration for a course page Dmc; (ii) the course duration rate Dc/Ds; (iii) the course consultation type Tc; (iv) the browsing pattern Fpc; and (v) the semantic proximity between the course and the content of the pages visited outside the course Prox. Details about their calculation methods could be found in (Bousbia et al. 2009).

The results of trace analysis of the fifth session of our experiment, used in this study, are presented in figure 3.

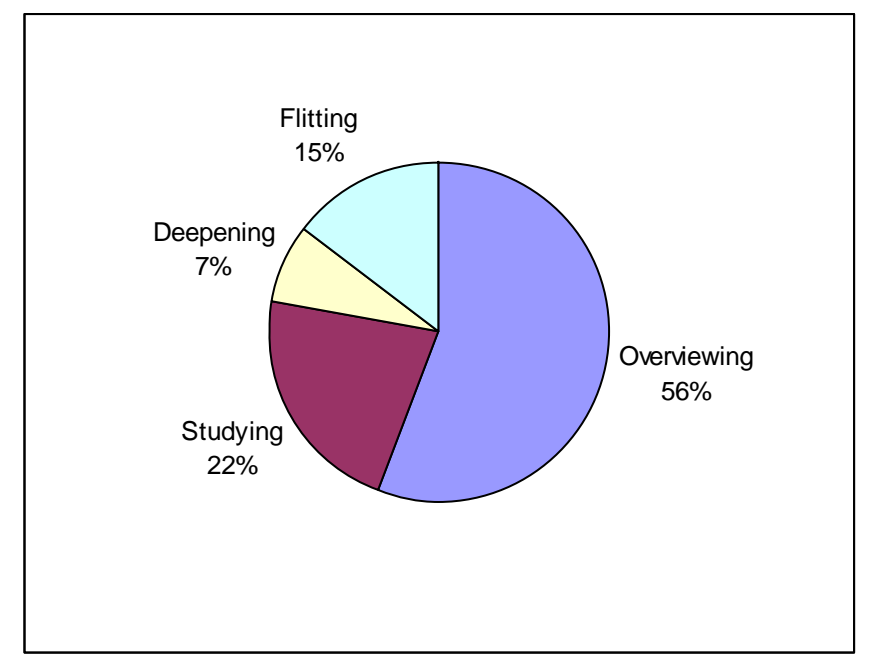

Figure 3. Session Distribution, According to the Navigation Type Indicator

We notice that a great part of the sessions are classified as overviewing (15 observations), then studying (6 observations), flitting (4 observations) and finally deepening ( 2 observations). This distribution can be due to the learners' will to discover the contents of this new part of the course before setting a clear objective, according to their interests. It can also result from their individual differences, which we are interested in here.

To check if the differences, in terms of learning styles, influence the navigation type used, we have to seek for significant relationships between the participants' learning style and the found navigation behaviours. The next step, in this study, deals with this point. 


\subsection{Learning Styles and Navigation Behaviours}

To investigate the relationships between the FSLSM and the navigation type, we present in the following subsections, the correlation analysis between each FSLSM dimension and the navigation behaviour found for each learner, using the navigation type indicator we have defined in 3 . However, we first introduce the definition of each dimension value, then we discuss the results.

\subsubsection{Active/Reflective Dimension}

This FSLSM dimension is used to describe the learner's preferred way to process information. Active learners tend to better retain and understand information by working actively with the learning material, applying, discussing or explaining it to others. In contrast, reflective learners prefer to think about and reflect on the learning material (Felder et Silverman 1988).

Figure 4 presents the students distribution according to their active/reflective preferences over the four navigation types found.

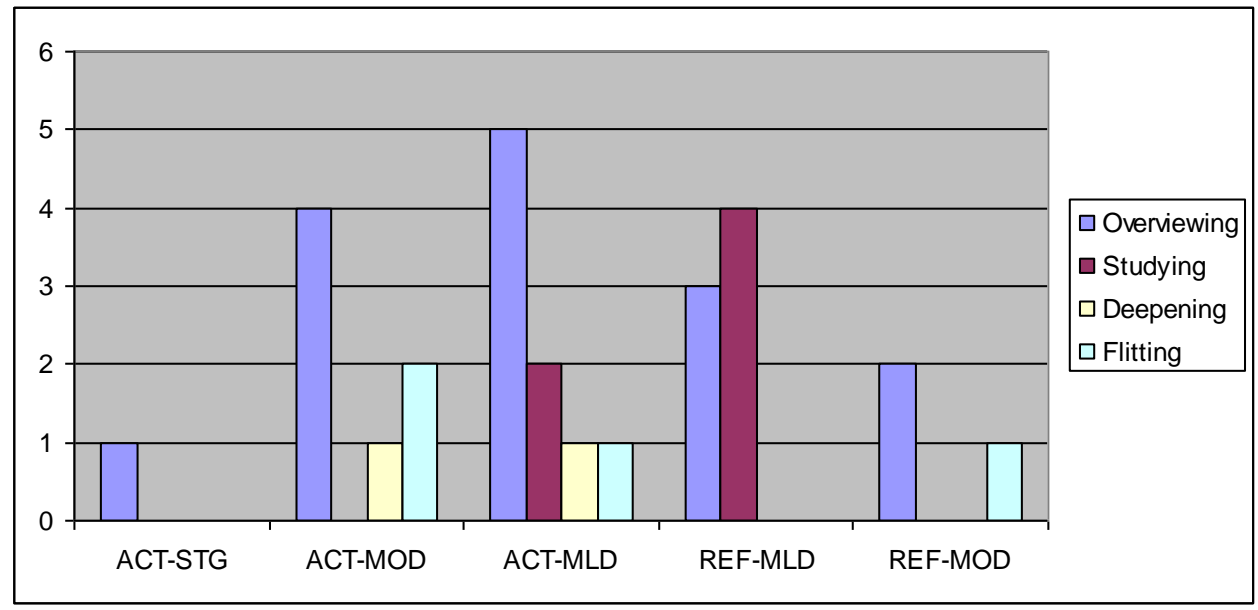

Figure 4. Distribution of the Active/Reflective Learning Style Dimension in terms of 'Navigation Type'

In this figure, when dealing with active learners, from left to right, we can say that: the subject having a strong preference (ACT-STG) adopted the overviewing navigation type; for the other 7 subjects, with moderate preference (ACT-MOD): 4 had an overviewing navigation type, the other 3 are distributed this way: 1 made a deepening navigation type, the other 2 a flitting one. Regarding the 9 students with mild preference for the active style (ACT-MLD), 5 adopted the overviewing navigation type, 2 the studying navigation type. About the last two students, a subject made a deepening navigation type, and the other made a flitting one.

When dealing with the reflective learners, among those having mild preference level (REF-MLD), 3 subjects adopted a navigation of overviewing type and the other 4, a studying navigation type. Concerning the three subjects with moderate preference for the reflective style (REF-MOD), 2 adopted an overviewing navigation type, and 1 a flitting.

This shows that students with an active style tend more to make an overviewing navigation type, considering each preference level either separately (STG, MOD and 
MLD) or by summoning the number of observations of subjects with active style. This result corresponds to their active preference of information processing, as they quickly and actively explore the contents. We also notice that subjects with moderate preference of the active style (ACT-MOD) use, in second position, the flitting navigation type. This can be justified, in the same way as the overviewing one, by their tendency to make several actions, such as visiting several URLs. However, subjects with mild preference of the active style (ACT-MLD) use, in second position the studying strategy. It can be due to the fact that these subjects tend more to have a reflective style, since the mild preference level is balanced between the two dimension axes. Indeed, the studying navigation type is more used by reflective students with mild preference that emphasizes our hypothesis. In fact, we expect that reflective students take more time to read and think about the contents rather than actively interact. However, we notice that the number of observations with overviewing navigation behaviour, for this style, is significant. The significant number of overviewing observations found during this experimentation may explain it.

Thus, we note that students with an active style tend more to adopt the overviewing navigation type, and those with a reflective style would rather prefer the studying navigation type. Nevertheless, as the majority of identified observations relate to the overviewing navigation type and the number of students with active style is more significant than the one with reflective style, this conclusion needs to be checked with a greater number of participants. Indeed, the result of the chi-2 independence test $(\chi 2=7.815, \mathrm{p}$-value $=0.287>0.05)$, shows no existence of dependence between the active/reflective LS dimension and the navigation type values.

\subsubsection{Sensing/Intuitive Dimension}

According to Felder and Silverman (1988), sensing learners prefer learning facts and solving problems by well-established methods. They are generally careful, practical, and patient and like new knowledge. They like to relate the learned material to the real world. Intuitive learners prefer to discover new relationships and can be innovative in their approach to problem solving. They tend to work faster and dislike repetition and tasks requiring great memorisation and routine calculations.

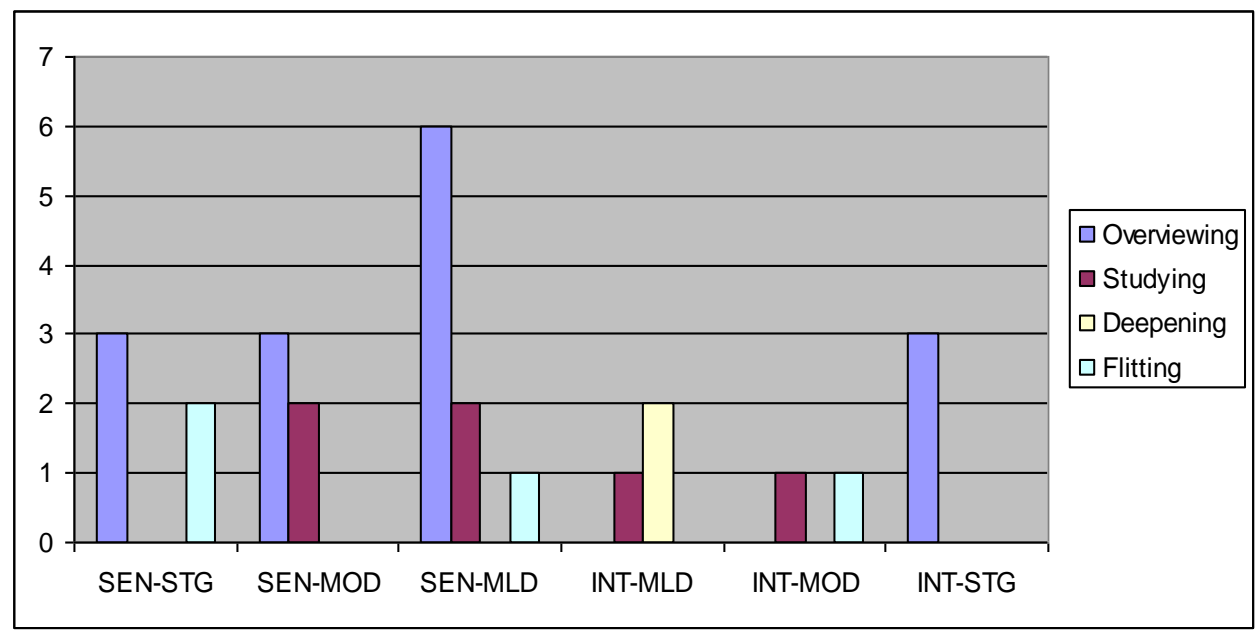

Figure 5. Distribution of the Observations in terms of 'Navigation Type' over the Sensing/Intuitive Learning Style Preference Level 
The distribution of the number of navigation types, found for each observation over the participants' preference levels of the sensing/intuitive learning style dimension, is presented in figure 5 .

This figure is read from left to right in the same way as in the preceding one. We also note, here, a strong presence for the overviewing behaviour for students having a sensing style, followed by flitting then studying ones. However, no subject adopted a deepening navigation type, which appears not correlated with the definition of this learning style. In fact, as sensing learner like new knowledge, we expected to find more deepening navigation behaviour, for which students search on the Web.

For subjects, having intuitive style, 2 out of the 3 , with mild preference, adopted a deepening navigation type, may be to discover new relations between the course concepts and the results of the Web search. However, for subjects with strong and moderate preference, this navigation type is not found. Those, with a moderate preference, adopted flitting and studying navigation behaviours, whereas all those, with strong preference, had an overviewing behaviour.

The results of the chi-square test $(\chi 2=24.996$, $p$-value $=0,016<0.05)$ indicate that the sensing/intuitive learning styles are dependent on the navigation type indicator. Thus, though we do not manage to clearly identify this dependence, we note that sensing/intuitive LS and navigation type indicator are really dependent. We should carry on the analysis of the whole experimentation traces in order to clearly state this dependence.

\subsubsection{Visual/Verbal Dimension}

Visual learners understand new information better by seeing it as pictures, demonstrations, diagrams, charts, films, etc; while verbal learners understand new information better through written and spoken words.

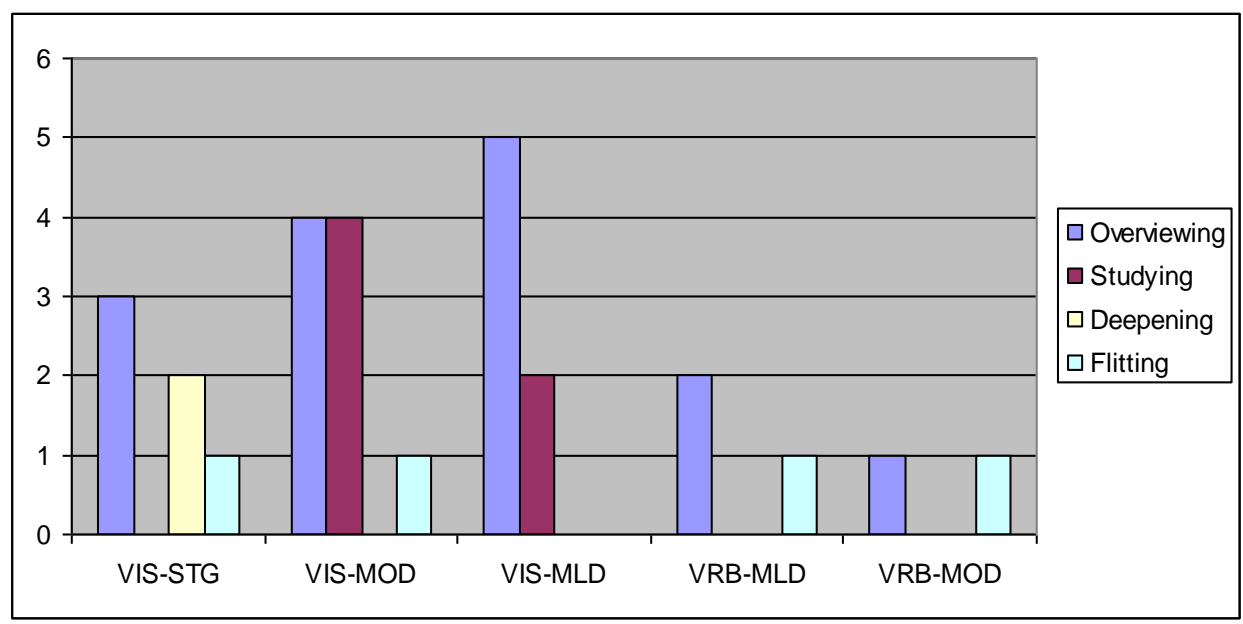

Figure 6. Distribution of the Observations in terms of 'Navigation Type' over the Visual/Verbal Learning Style Preference Level

According to these definitions, we have no hypothesis about the distribution of the observations on visual and verbal learners. However, as mentioned in section 2.3, this dimension has been studied by (Graff 2005) with respect to navigation strategies. He finds that users with a verbal style prefer a hierarchical structure, while those with a 
visual style prefer a relational structure of pages. However, the course, used in this experiment, has a hierarchical structure. So, we can check this finding, unless we consider the relational structure from a semantic point of view, thus this navigation strategy corresponds to a studying or a deepening navigation type. The results of our experiment are shown is figure 6.

We note that students with mild and moderate preference of visual learning style use more overviewing and studying navigation type. However, those with visual strong preference level also use deepening and flitting behaviours. For the verbal students, we find that they use overviewing or flitting navigation type, so they do not spend a long time on each page.

The finding for visual learners is interesting since it corroborates the considered results of (Graff 2005). However, for the verbal style, the small number of subjects does not allow us to make any conclusion. Consequently, the results of the chi-square test $(\chi 2=21.026$, $p$-value $=0.205>0.05)$ indicates that the visual/verbal learning styles are independent from the navigation type indicator.

\subsubsection{Sequential/global dimension}

Sequential learners understand new information in linear steps where each step follows logically the previous one. Global learners tend to learn in large jumps by absorbing material in a random order without necessarily seeing any connections until the whole concept has been grasped.

According to these definitions, we assumed that sequential learners tend to adopt the studying behaviour more than any other, and they may use the overviewing strategy as they tend to be active. However, global learners are more likely to use the other navigation types. To check this assumption, the experiment results are shown in figure 7.

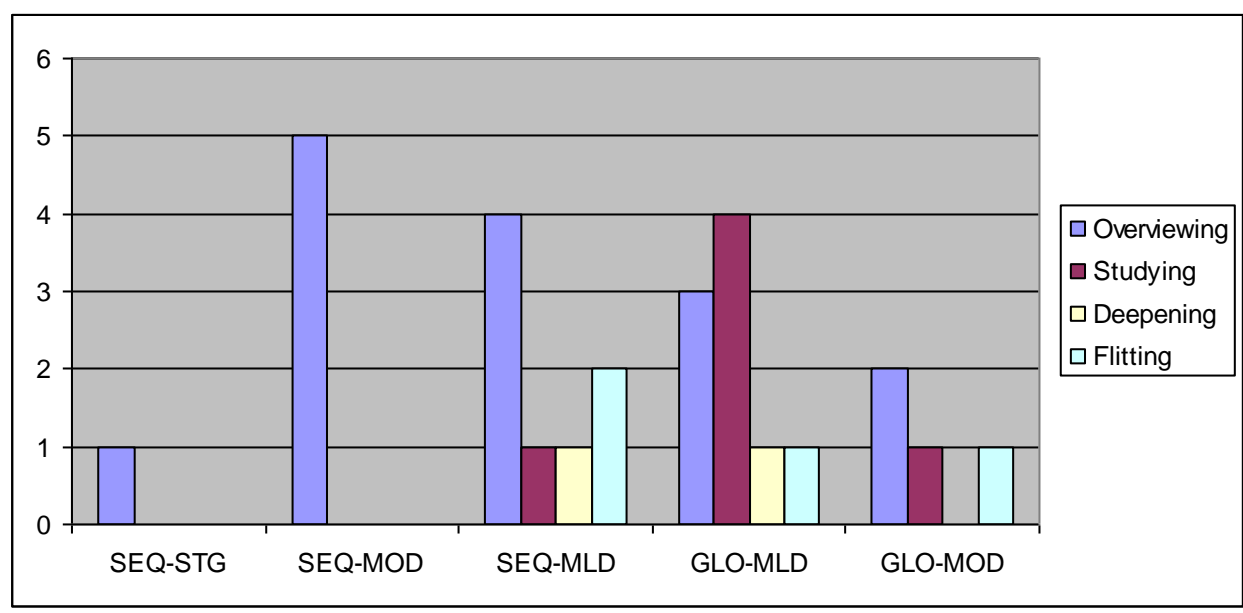

Figure 7. Distribution of the Observations in terms of 'Navigation Type' over the Sequential/Global Learning Style Preference Level

We find that sequential learners with strong and moderate preferences adopt overviewing behaviour. Those with mild preference tend to be like the global ones, who adopted all the navigation types. However, we note that global subjects with mild preference tend to be like sequential ones. the greater part of participants adopted the studying strategy. Thus, the results found strengthen the previous hypothesis. 
Nevertheless, the result of the chi-square test $(\chi 2=21.026, p$-value $=0.643>0.05)$ indicates that the sequential/global learning styles are independent from the navigation type indicator.

\section{Conclusions}

This study has demonstrated that relationships exist between learning styles and learners' navigation behaviour in Web-based environment. Although the chi-square dependency test shows the existence of such dependence only for the sensing/intuitive dimension over our sample, the distribution of the collected observations, in terms of navigation type, found by our indicators over the LS preference levels, affirms this dependence for all FSLSM dimensions. However, to identify these dependences clearly, we need to carry on the analysis of all the experimentation traces. We also need to make other experiments to check the existence of relationships with other learning style dimensions, and with other indicators. Thus, we can practically use this study findings, not only to automatically deduce the learner's learning style from the navigation type indicator - why not other necessary indicators- but to explain the learner's behaviour and take into account his/her learning style to adapt the content, as well.

\section{References}

1 Ayersman, D. J., \& von Minden, A. (1995). Individual differences, computers, and instruction. Computers in Human Behavior, 11 (3/4), 371-390.

2 Bousbia, N. (2005). Contribution théorique et méthodologique à l'élaboration d'un environnement de FOAD (Formation ouverte et à distance). Ecole nationale Supérieure d'Informatique (Esi ex INI), Algiers, Algeria.

3 Bousbia, N., \& J.M., Labat (2007). Perception de l'activité de l'apprenant dans un environnement de formation. In INRP eds, EIAH 2007, Lausanne, 07, pp. 233-238.

4 Bousbia, N., Labat, J-M., Rebai, I., \& Balla, A. (2008). How to determine the Learners' Learning Styles in e-Learning Situation? The 16th International Conference on Computers in Education, ICCE 2008, Taipei, Taiwan.

5 Bousbia, N., Labat, JM., Rebai, I., \& Balla A. (2009). Indicators for Deducting the Learners' Learning Styles: Case of the Navigation Typology Indicator. In Proceedings of the 9th IEEE International Conference on Advanced Learning Technologies ICALT 2009, pp 385-389.

6 Brown, E., Brailsford, T., Fisher, T., Moore, A., \& Ashman, H. (2006). Reappraising Cognitive Styles in Adaptive Web Applications. In Proceedings of the WWW 2006 Conference. pp. 327-335.

7 Brown, E., Cristea, A., Stewart, C. , \& Brailsford, T.J. (2005). Patterns in Authoring of Adaptive Educational Hypermedia: A Taxonomy of Learning Styles. Journal of Educational Technology and Society, 8(3), 77-90.

8 Brusilovsky, P., \& Millán, E. (2007). User models for adaptive hypermedia and adaptive educational systems. In A. K. a. W. N. Brusilovsky (Ed.), The Adaptive Web: Methods and Strategies of Web Personalization, Vol. 4321, pp. 3--53. Berlin Heidelberg, New York: Springer-Verlag.

9 Calcaterra, A., Antonietti, A., \& Underwood, J. (2005). Cognitive style, hypermedia navigation and learning. Computers \& Education, 44(4), 441-457. 
10 Carver, C. A., Howard, R.A. , \& Lane W.D. (1999). Addressing different learning styles through course hypermedia. IEEE Transactions on Education, 42(1), 33-38.

11 Cassidy, S. (2003). Learning styles: an overview of theories, models and measures. In Proceedings of the 8th Annual Conference of the European Learning Styles Information.

12 Chan-Lin, L. (1998). Students' cognitive styles and the need for visual control in animation. Educ Comput Res, 19(4), 351-363.

13 Chang, Y.-C., Kao, W-Y. Chu, C-P., \& Chiu, C-H. (2009). A learning style classification mechanism for e-learning. Computers \& Education, 53(2), 273-285.

14 Chen, S. Y., \& Liu, X. (2008). An integrated approach for modeling learning patterns of students in Web-based instruction: A cognitive style perspective. $A C M$ Transactions on Computer-Human Interaction (TOCHI), 15(1), 28.

15 Chen, S.Y., Magoulas, G. D. ,\& Macredie, R. D. (2004). Cognitive styles and users' responses to structured information representation. Int J Digit Libr, Springer-Verlag, 4, 93-107.

16 Chevrier, J., Fortin, G., Théberge, M., \& Le Blanc, R. (2000). Le style d'apprentissage : une perspective historique. Le style d'apprentissage, ACELF, XXVIII (1).

17 Chuang, Y.-R. (1999). Teaching in a multimedia computer environment: a study of effects of learning style, gender, and math achievement. Interactive Multimedia Electronic Journal of Computer-Enhanced Learning.

18 Clark, S., Seat, E. \& Weber, F. (2000). The performance of engineering students on the group embedded figures test. In Proceedings of the 30th Conference of the ASEE/IEEE Frontiers in Education, volume 1, pages T3A/1-T3A/4.

19 Coffield, F., Moseley, D., Hall, E., \& Ecclestone, K. (2004). Learning styles and pedagogy in post-16 learning. A systematic and critical review. : London: Learning and Skills Research Centre.

20 Curry, L. (1983). An organization of learning style theory and constructs. In L. C. (Ed.), Learning style in continuing medical education. Ottawa, Ontario: Council on Medical education, Canadian medical Association.

21 Dag, F., \& Geçer, A. (2009). Relations between online learning and learning styles. Social and Behavioral Sciences, 1, 862-871.

22 DeBello, T. C. (1990). Comparison of eleven major learning styles models: Variables, appropriate populations, validity of instrumentation, and research behind them. . Journal of Reading,Writing, and Learning Disabilities International, 6(3), 203-222.

23 Deture, M. L. (2004). Cognitive style and self-efficacy: Predicting student success in online distance education. Amer. J. Distance Educ. , 18(1), 21-38.

24 Dimitracopoulou et al. (2004). State of the Art on Interaction Analysis: Interaction Analysis Indicators, Deliverable: D.26.1, JEIRP-ICALTS, Kaleidoscope, july 2004, $148 \mathrm{p}$.

25 Draper, S. W. (1996). Observing, Measuring, or Evaluating Courseware: A Conceptual Introduction. . In G. Stoner (Ed.), Implementing Learning Technology, Learning Technology Dissemination Initiative (pp. 58-65).

26 Dufresne, A., \& Turcotte, S. (1997). Cognitive style and its implications for navigation strategies. In B. Boulay, and Mizoguchi, R. (Ed.), Artificial intelligence 
in education knowledge and media learning system (pp. 287-293). Kobe (Japan): IOS Press, Amsterdam.

27 Federico, P. (2000). Learning styles and student attitudes toward various aspects of network-based instruction. Computers in Human Behavior, 16(4), 359-379.

28 Felder, R. M., \& Silverman, L.K. (1988). Learning and Teaching Styles In Engineering Education. Engr. Education, 78(7), 674-681

29 Felder, R. M., Soloman, B. A. (1996). ILS: Index of Learning Styles, Retrieved 15 September, 2009, from http://www.engr.ncsu.edu/learningstyles/ilsweb.html.

30 Ford, N., \& Chen, SY. (2000). Individual differences, hypermedia navigation and learning: an empirical study. Educ Multimedia Hypermedia, 9(4), 281-311.

31 Frias-Martinez, E., Chen, S.Y. , \& Liu, X. (2009). Evaluation of a personalized digital library based on cognitive styles: Adaptivity vs. adaptability. . International Journal of Information Management, 29(1), 48-56.

32 Ghinea, G., \& Chen, S. Y. (2003). The impact of cognitive styles on perceptual distributed multimedia quality. British Journal of Educational Technology and Society, 34(4), 393-406.

33 Graf, S. (2007). Adaptativity in Learning Management Systems Foccussing on Learning Styles. Ph.D. Thesis, Vienna University of Technology, Austria.

34 Graff, M. (2005). Individual differences in hypertext browsing strategies. Behaviour and Information Technology, 24(2), 93 - 99.

35 Gregorc, A.F. (1979). Learning/Teaching Styles: Potent Forces behind Them. Educational Leadership, 36 (4), 234-236.

36 Honey, P., and Mumford, A. (1992). The Manual of Learning Styles. Maidenhead: Peter Honey Publications.

37 Hwang, W., Wang, C., \& Sharples, M. (2007). A study of multimedia annotation of Web-based materials. Comput\&Educ., 48(4), 680-699.

38 Jonassen, D. H., \& Grabowski, B. L. (1993). Handbook of Individual Differences, Learning, and Instruction. Lawrence Erlbaum Associates, Hillsdale, New Jersey.

39 Kolb, D. A. (1984). Experiential learning: experience as the source of learning and development. New Jersey: Prentice Hall.

40 Korthauer, R. D., \& Koubek, R. J. (1994). An empirical evaluation of knowledge, cognitive style and structure upon the performance of a hypertext task. International Journal of Human Computer Interaction, 6, 373 - 390.

41 Kraus, L. A., Reed, W.M., \& Fitzgerald, G.E. (2001). The effects of learning style and hypermedia prior experience on behavioral disorders knowledge and time on task: a case-based hypermedia environment. Computers in Human Behavior , 17(1), 125-140.

42 Lee, C. (1994). The effects of auditory cues in interactive multimedia and cognitive style on reading skills of third graders. Unpublished EdD dissertation University Of Pittsburgh, PA.

43 Lee, C., Cheng, Y. W., Rai, S., \& Depickere, A. (2005). What affect student cognitive style in the development of hypermedia learning system? . Comput\&Educ. , 45(1), 1-19.

44 Liegle, J., \& Janicki, T. (2006). The Effect of Learning Styles on the Navigation Needs of Web-Based Learners. Computers and Human Behavior, 22(5), 885-898. 
45 Liu, M., \& Reed, W.M. (1994). The effect of hypermedia assisted instruction on second-language learning through a semantic-network-based approach. J. Educ. Comput. Res., 12(2), 159-175.

46 Lu, J., Yu, C.S., \& Liu, C. (2003). Learning style, learning patterns, and learning performance in a WebCT-based MIS course. Information and Management, 40(6), 497-507.

47 Marrison, D., \& Frick, M.J. (1994). The effect of agricultural students' learning styles on academic achievement and their perceptions of two methods of instruction. J Agric Educ, 35(1), 26-30.

48 Merrill, M. D. (2002). Instructional Strategies and Learning Styles: Which Takes Precedence? In R. (Eds.), Trends and Issues in Instructional Technology. Columbus, OH, Prentice Hall, pp. 99-106.

49 Miller, L. M. (2005). Using learning styles to evaluate computer-based instruction. Computers in Human Behavior, 21(2), 287-306.

50 Palmquist, R., \& Kim, K-S. (2000). Cognitive style and on-line database search experience as predictors of Web search performance. J Am Soc Inf Sci, 51(6), 558566.

51 Papanikolaou K.A., G. M., Kornilakis H. , \& Magoulas G. D. (2003). Personalizing the inter-action in a Web-based educational hypermedia system: the case of INSPIRE. In Proceeding of the User-Modelling and User-Adapted Interaction conference.

52 Paredes, P., \& Rodríguez, P. (2004). A mixed approach to modelling learning styles in adaptive educational hypermedia. Advanced Technology for Learning, 1(4), 210215.

53 Pask, G. (1976). Styles and Strategies of Learning. British Journal of Educational Psychology, 46, 128-148.

54 Peterson, E. R., \& Deary, I.J. (2006). Examining wholistic-analytic style using preferences in early information processing. Personality and Individual Differences, 41(1), 3-14.

55 Pithers, R. T. (2002). Cognitive learning style: a review of the field dependent-field independent approach. Journal of Vocational Education and Training, 54(1), 117132.

56 Popescu, E. (2008). Dynamic adaptative hypermedia systems for e-learning. Criova, Romania.

57 Popescu, E. (2009). Learning Styles and Behavioral Differences in Web-Based Learning Settings. In Proceedings of the 2009 Ninth IEEE International Conference on Advanced Learning Technologies, ICALT 2009, 446-450.

58 Popescu, E., Badica, C., \& Trigano (2007). Rules for Learner Modeling and Adaptation Provisioning in an Educational Hypermedia System. In Proceedings of the Ninth International Symposium on Symbolic and Numeric Algorithms for Scientific Computing, 492-499.

59 Reed, W. M., Oughton, J.M, Ayersman, D.J., Ervin, J.R., Giessler, S.F. (2000). Computer experience, learning style, and hypermedia navigation. Computers in Human Behavior, 16(6), 609-628.

60 Reed, W., \& Oughton, JM. (1997). Computer experience and interval-based hypermedia navigation. Res Comput Educ, 30(1), 38-52. 
61 Rich, E. (1983). Users are individuals: individualizing user models. International Journal of Man-Machine Studies, 18(3), 199-214.

62 Riding, R., \& Rayner, S. (2001). Cognitive styles and learning strategies. David Fulton Publishers, London.

63 Sangineto, E., Capuano, N., Gaeta, M., \& Micarelli, A. (2007). Adaptive Course Generation through Learning Styles Representation. Journal of Universal Access in the Information Society, 7(1/2), 1-23.

64 Stash, N., Cristea, A., \& de Bra, P. (2006). Adaptation to Learning Styles in ELearning: Approach Evaluation. . In Proceedings of the World Conference on ELearning in Corporate, Government, Healthcare, and Higher Education, VA, AACE, 284-291.

65 Tinajero, D. C. \& Paramo, M. F. (1997). Field dependence-independence and academic achievement: a re-examination of their relationship. British Journal of Educational Psychology, 67(2), 199-212.

66 Triantafillou, E., Pomportsis, A., \& Demetriadis, S. (2003). The design and the formative evaluation of an adaptive educational system based on cognitive styles. Computers \& Education, 41(1), 87-103.

67 Tyndiuk, F. (2005). Référentiels Spatiaux des Tâches d'Interaction et Caractéristiques de l'Utilisateur influençant la Performance en Réalité Virtuelle. $\mathrm{Ph} . \mathrm{D}$ thesis on Cognitive sciences, Bordeaux 2 University, France.

68 Wang, T.-I., Wang, K-T., \& Huang, Y-M. (2008). Using a style-based ant colony system for adaptive learning. Expert Systems with Applications, 34(4), 2449-2464.

69 Witkin, H. A., Oltman, P. K., Raskin, E., \& Karp, S. A. (1971). A Manual For The Group Embedded Figures Test. Consulting Psychologists Press, Palo Alto, CA. 